\section{Describing chemical methods}

Methodicum Chimicum: A Critical Survey of Proven Methods and their Application in Chemistry, Natural Science, and Medicine. Edited by Friedhelm Korte. Volume 1: Analytical Methods. Part A: Purification, Wet Processes, Determination of Structure. Pp. $x+1-628$. Part B: Micromethods, Biological Methods, Quality Control, Automatisation. Pp. $\mathrm{x}+629-1218$. (Academic: New York and London; Georg Thieme: Stuttgart, 1975.) \$98; $£ 47.05$ the two parts.

Volumes IA and $1 \mathrm{~B}$ comprise the start of an eleven-volume series which will give "a short critical description of chemical methods applied in scientific resarch and practice", the objective being "to provide the chemist and the scientist working in related areas of chemistry with a rapid and reliable source of information on the method applicable to his specific problem."

The subtitles of volumes $1 \mathrm{~A}$ and $1 \mathrm{~B}$ "Analytical Methods", is somewhat misleading, especially for $1 \mathrm{~A}$, as it is used in the sense of integral identification of a molecular entity and not in that of conventional chemical analysis; moreover the emphasis is strongly biased towards organic and biological chemistry. With these reservations the editors and about 100 contributors, almost entirely European, have managed to compress into 1,200 pages a vast quantity of well presented information. The methods discussed, some of the less well known purposely given in greater detail than others, range from simple chemical operations to highly sophisticated instrumental techniques. The individual chapters provide a guidance to workers in the selection of methods appropriate to the problem being tackled and at the same time give sufficient theoretical background to enable the user to judge whether or not he can use the selected procedure himself or must employ the services of a specialist in the chosen field.

Part A deals with small-molecule separation, identification and structural analysis. Chemical and other methods are described for functional groups, but specialised techniques such as X-ray diffraction (40 pages) and various spectroscopic methods (200 pages) are dealt with in greater detail.

Part B first discusses some special physical methods covering such diverse topics as the determination of molecu- lar weights, electron donor-acceptor complexes and electric dipole moments. Thereafter it deals with specific chemical, instrumental or biochemical techniques for the determination of both trace elements and organic constituents in a wide variety of organic samples including foods, fats, water, fuel and pharmaceuticals.

The work will provide a source of condensed information on newer techniques and, although it will not replace specialised monographs, adequate references up to 1969 , sometimes up to 1972 , are supplied for readers desiring more detailed information. The 53-page index, however, has omissions, no reference for example being given to the section on the use of flame photometry and atomic absorption for the analysis of fuel oils on p.955. The high cost of $£ 48.05$ will be beyond most private buyers but is justified by the amount of work that has been carried out by the authors and editors. The quality of production is excellent although somewhat marred by spelling errors and by the use of the symbol $\mathbf{J}$ for iodine in several places. If the following volumes maintain the quality of Volumes IA and 1B, the series will become a reference work of major importance for all multidiscipline establishments.

\section{Molecular complexes}

Molecular Association. Volume 1. Edited by R. Foster. Pp. xiv +365 . (Academic: London, New York and San Francisco, August 1975.) £11.80; $\$ 31.25$.

THIS book contains four articles dealing with various aspects of electrondonor-acceptor (EDA) molecular complexes or charge-transfer (CT) complexes as they are commonly, but imprecisely, known, and with other molecular complexes. Z. G. Soos (Princeton) and D. J. Klein (Austin) give a detailed account (109pp, 340 refs) of charge transfer in solid-state complexes. This includes a phenomenological theory, a classification of $\pi$-molecular CT crystals, one-dimensional Hubbard models, magnetic properties of CT crystals, and the computation of model parameters. N. Kulevsky (Grand Forks) describes the dielectric properties of molecular complexes in solution, with particular reference to halogen complexes, complexes of $\pi^{*}$-acceptors, and halogenated alkane interactions $(50 \mathrm{pp}, 103$ refs). K. M. C. Davis (Leicester) discusses solvent effects on 'CT complexes', including the position and intensity of the CT absorption and fluorescence bands, charge-transferto-solvent (CTTS) spectra, vibrational spectra of complexes, nuclear magnetic resonance shifts, thermodynamic parameters, and complex-solvent interactions ( $63 \mathrm{pp}, 334$ refs). R. S. Davidson (Leicester) provides a comprehensive survey of photochemical reactions involving ' $\mathrm{CT}$ complexes' (120 pp, 449 refs). These are classified into reactions involving excited ' $\mathrm{CT}$ complexes', excimers (intermolecular and intramolecular) and exciplexes (subdivided into those with and without spectroscopic evidence).

There have been several recent books on molecular complexes, three of them written (Organic ChargeTransfer Complexes, Academic: London and New York, 1969) or edited (Molecular Complexes, 1 and $\mathbf{2 ,}$ Elek Science, London; Crane Russak, New York, 1973 and 1974) by $\mathbf{R}$. Foster, who has skilfully chosen the authors and contents of the present volume to cover topics he has not previously considered. It is doubtful whether there are sufficient gaps remaining in the literature to justify the initiation of a new series of volumes on molecular complexes under a different title selected "for bibliographical convenience." Molecular Complexes, Vol. 3, would have been a more accurate and convenient title for the present book. J. B. Birks

\section{BOOKS ON PURE AND APPLIED SCIENCE}

Books reviewed or mentioned in this journal are available from stock.

Catalogues on application.

Please state interests.

\section{SCIENTIFIC LIBRARY}

ANNUAL SUBSCRIPTION from $£ 5.00$

Reduced rates for multiple subscriptions

Availablo in U.K. only

Prospectus free on request

\section{H. K. LEWIS \& Co. Ltd. LONDON: 136 GOWER STREET, WC1E 6BS}

Telephone: $01-3874282$ 